Article

\title{
Evaluation of the Suitability of Poly(Lactide)/Poly(Butylene-Adipate-co-Terephthalate) Blown Films for Chilled and Frozen Food Packaging Applications
}

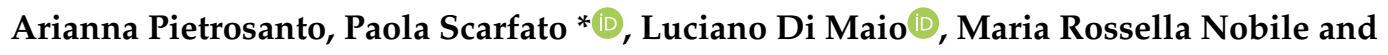 \\ Loredana Incarnato \\ Department of Industrial Engineering, University of Salerno, Via Giovanni Paolo II, 132, 84084 Fisciano (SA), \\ Italy; arpietrosanto@unisa.it (A.P.); ldimaio@unisa.it (L.D.M.); mrnobile@unisa.it (M.R.N.); \\ lincarnato@unisa.it (L.I.) \\ * Correspondence: pscarfato@unisa.it
}

Received: 20 December 2019; Accepted: 12 March 2020; Published: 3 April 2020

\begin{abstract}
The use of biopolymers can reduce the environmental impact generated by plastic materials. Among biopolymers, blends made of poly(lactide) (PLA) and poly(butylene-adipate-co-terephthalate) (PBAT) prove to have adequate performances for food packaging applications. Therefore, the present work deals with the production and the characterization of blown films based on PLA and PBAT blends in a wide range of compositions, in order to evaluate their suitability as chilled and frozen food packaging materials, thus extending their range of applications. The blends were fully characterized: they showed the typical two-phase structure, with a morphology varying from fibrillar to globular in accordance with their viscosity ratio. The increase of PBAT content in the blends led to a decrease of the barrier properties to oxygen and water vapor, and to an increase of the toughness of the films. The mechanical properties of the most ductile blends were also evaluated at $4{ }^{\circ} \mathrm{C}$ and $-25^{\circ} \mathrm{C}$. The decrease in temperature caused an increase of the stiffness and a decrease of the ductility of the films to a different extent, depending upon the blend composition. The blend with $40 \%$ of PLA revealed to be a good candidate for chilled food packaging applications, while the blend with a PLA content of $20 \%$ revealed to be the best composition as frozen food packaging material.
\end{abstract}

Keywords: biopolymers; PLA/PBAT; blown films; food packaging; film for frozen food

\section{Introduction}

In recent years, the growing interest of the population towards environmental issues, and the increasingly stringent directives that various countries are adopting to fight against environmental pollution deriving from plastic materials, have directed research towards the development of ecofriendly materials that can substitute the conventional plastic ones [1]. The packaging sector is the one that uses the highest amount of plastic [2], and thus, the use of so-called "biopolymers" in the food packaging field could be a strategy to reduce the environmental impact generated by the traditional plastics materials [3]. Moreover, since a considerable amount of foods requires sub-ambient storage temperatures (e.g., chilled and frozen food), the retention of satisfactory performance properties at low temperatures has a key role to extending the range of applications of a material in the food packaging field.

Different examples can be found in literature on the effect of sub-ambient temperature upon the mechanical and barrier response of conventional polyolefin-based systems [4-7], since, currently, these are the most employed materials for low temperature packaging applications. 
As a general trend, in terms of mechanical response, the temperature lowering gives a decrease in the material ductility and shock absorption power; instead, in terms of barrier properties, it gives a decrease of permeability to gases and a change in perm-selectivity. To our best knowledge, no literature data are available on the effect of sub-ambient temperatures on the functional performances of biopolymer-based packaging systems, and their applications for refrigerated food storage are still very limited.

Among the biopolymers, PLA is one of the most promising and widespread ones that can replace petrochemical plastics [8-10]. PLA is a compostable and bio-based polymer, it is a linear aliphatic polyester, and its properties can be turned varying the relative content of $\mathrm{D}$ - and L-enantiomers [11]. It can be easily processed with conventional process such as extrusion, spinning, injection and compression molding [12-15]. However, its high brittleness limits its use, thus different strategies are tested in order to improve its toughness [16-19]. Among them, blending of PLA with PBAT has shown promising results.

PBAT is a compostable aliphatic aromatic co-polyester that consists of two types of comonomer, a rigid butylene terephthalate segment made of 1.4 butanediol and terephthalic acid monomers, and a flexible butylene adipate section made of 1.4 butanediol and adipic acid monomers [20]. This polymer is flexible and tough, and it has complementary properties to PLA [21].

Several researchers have blended PLA with PBAT, through several techniques, like single-screw extrusion, twin-screw extrusion and solvent casting [20,22-26]. Results showed that, even if these polymers have very close solubility values [27], they are not thermodynamically miscible.

Li et al. [28] studied the morphology of this system in a wide range of compositions. They showed that for a PBAT content lower than $20 \mathrm{wt} \%$, the blend surface appeared uniform, characterized by the presence of featured small droplets suspended in the continuous phase. When the PBAT content increased between 20 and $50 \mathrm{wt} \%$, the system became heterogeneous, with a co-continuous phase structure formed at $50 \mathrm{wt} \%$. Furthermore, when the PBAT content exceeded $70 \mathrm{wt} \%$, the morphology turned into droplets. In addition, Deng at al. [29] investigated the morphology of these systems, and they found a fibrillar morphology with a co-continuous phase structure when the PBAT content was between $20 \mathrm{wt} \%$ and $40 \mathrm{wt} \%$, and PLA dispersed particles in the PBAT matrix when the content of the latter polymer was between $60 \mathrm{wt} \%$ and $80 \mathrm{wt} \%$.

However, even if these polymers are not miscible, their blending allows us to obtain several advantages. Hongdilokkul et al. [30] reported that the addition of $20 \mathrm{wt} \%$ of PBAT into the PLA matrix considerably improved the processability for film blowing by increasing the melt strength of the system. Moreover, the presence of PBAT influenced the crystallization behavior of PLA; in fact, it is reported that PBAT can act as a nucleating agent for PLA [30,31], increasing its crystallization rate.

Furthermore, several works deal with the mechanical properties of this system. Wang et al. [32] have melt blended PLA and PBAT, and showed that the brittleness and ductility of PLA could be improved by adding $10 \%$ PBAT, which increased the elongation at break from $7.71 \%$ to $357.8 \%$, and decreased the tensile strength from 65.21 MPa to 47.52 MPa. Li et al. [33] have analyzed a wide range of the composition of PLA/PBAT blends, showing an increase of the elongation at break with the PBAT content in the blend, and a reduction of the elastic modulus that, in the blend with the 20\% of PBAT, was decreased of more than $30 \%$ compared to the pure PLA. Farsetti et al. [34] made an impact analysis, and they reported an increase of the GIC (critical release rate of strain energy) value at compositions ranging from neat PLA down to PLA mass fraction equal to 0.8 , due to a toughening effect of PBAT. In general, the addition of PBAT lead to an increase of the ductility, but to a decrease of the elastic modulus in the tensile strength of the blends.

Moreover, interesting results of these blends are reported also for the food packaging field. Tabasi et al. [35] reported that the sealability properties of PLA/PBAT blends can be tailored by varying the blend composition and PBAT crystallinity degree. Higher content of PLA in the blend and the lower crystallinity of PBAT provide lower hot-tack initiation temperature. 
Li et al. [33] investigated the oxygen permeability of these blends in a wide range of compositions, and with the addition of the $0.15 \mathrm{wt} \%$ of a compatibilizer, they found that the oxygen permeability of PBAT was two times higher than PLA, and the permeability of the blends increased as the content of PBAT in the blend increased. Wang et al. [23] reported that the presence of PBAT can considerably improve the UV-screening properties compared to neat PLA and PLA/PBAT films, which proved to be effective in preventing the greening of fresh potatoes. Moreover, the high-water vapor permeability of these films can be useful to prevent fogging on the surface of packaging film, as revealed for fresh, green onions.

However, there is a lack of literature on the effect of the temperature on the mechanical properties of these systems. Only Gigante et al. [36] studied the effect of temperature on the fracture behavior of different PLA/PBAT blends, in which PLA was the matrix phase. By the estimation of the ductile-to-brittle transition temperature (DBTT), they highlighted that the ductile behavior for these blends appeared at temperatures higher than the PBAT glass transition temperature, and particularly, for the blends with a PBAT content between $15 \mathrm{wt} \%$ and $25 \mathrm{wt} \%$, this happened around $-23{ }^{\circ} \mathrm{C}$.

Moreover, the decrease of the ductility is a problem particularly relevant for materials with low thickness, so for the flexible packaging. Thus, the knowledge of the mechanical behavior at low temperatures is essential information to evaluate the suitability for packaging foods requiring low storage temperatures.

Therefore, in this work, PLA/PBAT blown films in a wide range of compositions were developed and fully characterized, and the mechanical properties of the most ductile films were evaluated at three different temperatures $\left(25^{\circ} \mathrm{C}, 4^{\circ} \mathrm{C}\right.$ and $\left.-25^{\circ} \mathrm{C}\right)$, in order to extend the range of application of these blends for chilled and/or frozen food flexible packaging.

\section{Experimental}

\subsection{Materials}

PLA 4032D, supplied by NatureWorks ${ }^{\mathrm{TM}}$ (Minnetonka, MN, USA), has a content of D-isomer equal to $1.5 \mathrm{wt} \%$, a specific gravity of $1.24 \mathrm{~g} / \mathrm{cm}^{3}$ and a melting temperature between $155-170{ }^{\circ} \mathrm{C}$. Ecoworld PBAT 009 was manufactured by Jin Hui Zhaolong (Lüliang, China); it is composed by the $29 \%$ of adipic acid, $26 \%$ of terephthalic acid and $45 \%$ of 1,4-butanediol, it has a density of $1.26 \mathrm{~g} / \mathrm{cm}^{3}$ and a melting temperature around $110-120^{\circ} \mathrm{C}$. Both materials comply with USA Food and Drug Administration (FDA) and European Union (EU) regulations for direct food contact. They also conform the standards of compostability under controlled composting conditions, i.e., standards EN13432 and ASTM D 6400.

\subsection{Preparation of the Films}

PLA and PBAT pellets were dried under vacuum at $70{ }^{\circ} \mathrm{C}$ for $20 \mathrm{~h}$ prior to processing. PLA and PBAT at different PLA/PBAT concentrations (100/0, 80/20, 60/40, 40/60 20/80 0/100 by weight) were mixed in a Collin ZK25 co-rotating twin extruder $(\mathrm{D}=25 \mathrm{~mm}, \mathrm{~L} / \mathrm{D}=42)$, with a screw speed equal to $100 \mathrm{rpm}$, a temperature profile ranging from $140{ }^{\circ} \mathrm{C}$ to $190{ }^{\circ} \mathrm{C}$, and a mass flow ranging from 50 to $54 \mathrm{~g} / \mathrm{min}$. Then, the materials were cooled in a water bath. After, pure materials and each blend were dried under vacuum at $70^{\circ} \mathrm{C}$ for $20 \mathrm{~h}$ before processing. The blown films were prepared in a multilayer plant, using two single screw extruders GIMAC $(\mathrm{D}=12 \mathrm{~mm}, \mathrm{~L} / \mathrm{D}=24)$, with a screw speed equal to $50 \mathrm{rpm}$ and a take up speed of $1 \mathrm{~m} / \mathrm{min}$. The temperature profile ranged from $190^{\circ} \mathrm{C}$ to $180^{\circ} \mathrm{C}$ for pure PLA, from $180^{\circ} \mathrm{C}$ to $135^{\circ} \mathrm{C}$ for the blends and from $160^{\circ} \mathrm{C}$ to $125^{\circ} \mathrm{C}$ for pure PBAT. Films were produced with a blow-up ratio (BUR) and a take-up ratio (TUR) equal to 2.5 and with constant thickness of $75 \pm 5 \mu \mathrm{m}$. 


\subsection{Rheological Characterization}

The rheological properties in the oscillatory mode of pellets of PLA, PBAT and their blends were evaluated using an oscillatory shear strain-controlled rheometer, ARES. Samples were dried under vacuum at $70^{\circ} \mathrm{C}$ for $16 \mathrm{~h}$ prior to testing. Tests were performed with a parallel-plate geometry $(\mathrm{d}=25$ $\mathrm{mm}$ ) with a gap of $1 \mathrm{~mm}$ at $180^{\circ} \mathrm{C}$ under a nitrogen atmosphere, in order to minimize thermo-oxidative degradation. A strain sweep test was initially conducted to guarantee the linear viscoelastic regime for each formulation. Frequency sweep tests were conducted in triplicate, with a standard deviation less than $2 \%$.

\subsection{Differential Scanning Calorimetry (DSC)}

Thermal analysis on the pellets of pure materials and their blends and on the produced films was performed using a Differential Scanning Calorimeter (DSC mod. 822, Mettler Toledo, Columbus, OH, USA) under a nitrogen gas flow $(100 \mathrm{~mL} / \mathrm{min})$, in order to minimize thermo-oxidative degradation phenomena. The temperature programming consisted of three steps: The samples were heated from -70 to $200{ }^{\circ} \mathrm{C}$ with a speed of $10^{\circ} \mathrm{C} / \mathrm{min}$, and held at $20{ }^{\circ} \mathrm{C}$ for $5 \mathrm{~min}$. They were then cooled at -70 at $10^{\circ} \mathrm{C} / \mathrm{min}$, and reheated to $200^{\circ} \mathrm{C}$ at $10{ }^{\circ} \mathrm{C} / \mathrm{min}$. The crystallinity degrees, $\mathrm{X}_{\mathrm{c}}$, were calculated according to the following formula:

$$
X c=\frac{\Delta H m-\Delta H c c}{\Delta H m^{0} \times \varphi i} \times 100
$$

where $\Delta H \mathrm{~m}$ and $\Delta H \mathrm{cc}(\mathrm{J} / \mathrm{g})$ are the respective heat of melting and heat of cold crystallization of PBAT and PLA, the $\Delta \mathrm{Hm}^{0}$ is equal to $93.6 \mathrm{~J} / \mathrm{g}$ for PLA [37] and 114 for PBAT [38], and $\varphi i$ is the relative weight fraction of PLA or PBAT in the blends.

\subsection{Fourier Transformation Infrared Spectroscopy (FT-IR)}

Infrared spectra of the film of pure materials and their blends were obtained with a Thermo Nicolet NEXUS 600 spectrometer in attenuated total reflectance (ATR) mode, with a diamond crystal collecting 64 scans. Each spectrum was obtained within the range of $4000-400 \mathrm{~cm}^{-1}$ with the wavelength resolution of $4 \mathrm{~cm}^{-1}$.

\subsection{Morphological Characterization}

Film samples were cryo-fractured and then coated with a thin gold layer (Agar Auto Sputter Coater mod. 108 A, Stansted, UK) at $30 \mathrm{~mA}$ for $160 \mathrm{~s}$ to improve their conductivity. Afterwards, their cross sections parallel to the transversal direction (TD) were scanned by field emission scanning electron microscope (FESEM) (LEO 1525 model, Carl Zeiss SMT AG, Oberkochen, Germany). Length evaluation was performed through the SigmaScan Pro $^{\mathrm{TM}}$ Software.

\subsection{Oxygen Transmission Rate (OTR)}

OTR measurements were carried out through a permeabilimeter (GDP-C 165 of Brugger), with a manometric operation, connected to a thermo-controlled bath (ThermoHaake). Before testing, the evacuation of the upper and the bottom half-cell was performed to drive away humidity and residual gases. The test temperature was set at $23^{\circ} \mathrm{C}$, and the oxygen flow to $80 \mathrm{~mL} / \mathrm{min}$, according to ISO 15105-1. The area of the tested films was $9 \mathrm{~cm}^{2}$. The values of the permeability coefficients $\left(\mathrm{P} \mathrm{O}_{2}\right)$ were obtained by multiplying the measured value of OTR by the respective thicknesses $(\mathrm{mm})$ of the films.

\subsection{Water Vapor Transmission Rate (WVTR)}

Water vapor permeability tests were performed through a Water Vapor Permeation Analyzer (Model 7002-Systech Illinois, Princeton, NJ, USA), which provides a modular system for the determination of water vapor permeability using a sensor based upon $\mathrm{P}_{2} \mathrm{O}_{5}$. Tests were carried 
out according to ASTM F 1249-90 standard (with the only exception of sensor technology) at $23^{\circ} \mathrm{C}$ and $50 \%$ of relative humidity. The area of the tested films was $5 \mathrm{~cm}^{2}$. The values of the permeability coefficients $\left(\mathrm{P} \mathrm{H}_{2} \mathrm{O}\right)$ were obtained by multiplying the measured value of WVTR by the respectively thickness $(\mathrm{mm})$ of the films.

\subsection{Mechanical Properties}

Tensile testing of blown films was performed on a SANS dynamometer (Sans Testing Machine Co. Ltd., Shenzhen, China) equipped with a $100 \mathrm{~N}$ load cell. The rectangular shape specimens (width $=12.7 \mathrm{~mm}$ and length $=30 \mathrm{~mm}$ ) were extended at a crosshead speed set according to ASTM D822 standard. Mechanical properties were evaluated in the machine direction (MD).

Tests were carried out at ambient temperature $\left(25^{\circ} \mathrm{C}\right)$ and at controlled environment temperatures $\left(4{ }^{\circ} \mathrm{C}\right.$ and $\left.-25{ }^{\circ} \mathrm{C}\right)$, using an Environmental chamber connected to a WK650 High Precision Temperature controller and to a Liquid nitrogen container. All of the data are the average of at least seven measurements.

\section{Results and Discussion}

\subsection{Rheological Characterization of the Pellet}

Rheological oscillatory analysis was carried out to investigate the morphology and processability of the blends. First, a dynamic strain sweep test was performed for both the pure materials at a frequency of $10 \mathrm{rad} / \mathrm{s}$, with the aim to determine the limit of linear viscoelasticity that was found to be greater than $5 \%$ of deformation. Thus, all of the rheological tests were performed at a strain equal to $5 \%$. Dynamic time sweep tests were then performed to investigate the thermal stability during the flow in an inert atmosphere at the rate of $1 \mathrm{rad} / \mathrm{s}$. These tests revealed a percentage of complex viscosity reduction in a time of $7 \mathrm{~min}$ (duration of a frequency sweep test) of less than $1 \%$ for both materials. Frequency sweep tests were then performed with a frequency ranging from 0.1 to $100 \mathrm{rad} / \mathrm{s}$. The trend of the complex viscosity versus the frequency is reported in the Figure 1.

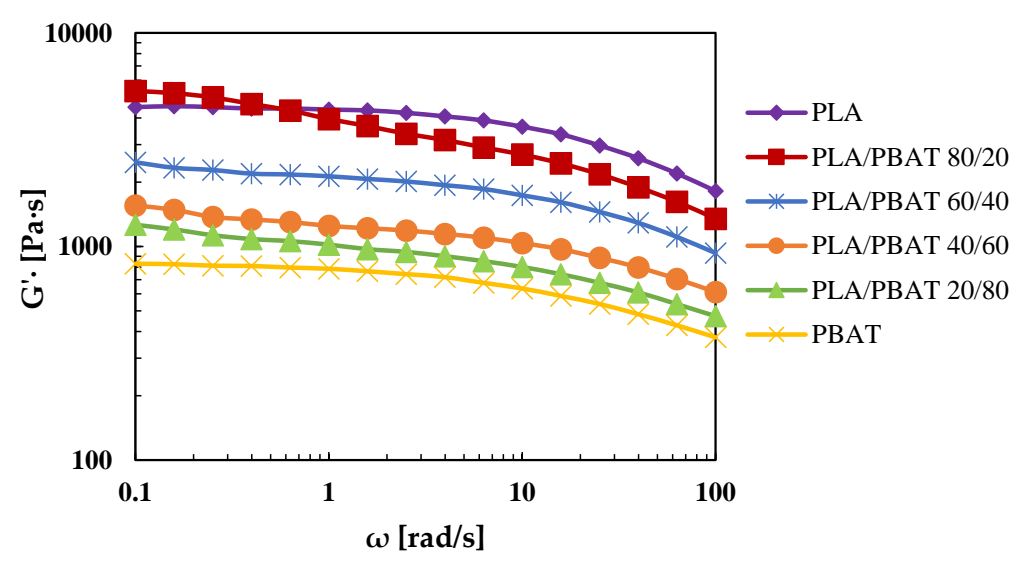

Figure 1. Complex viscosity of the extruded pellets.

Results show that both the pure materials exhibit shear thinning behavior, and a low-frequency Newtonian plateau. Furthermore, it is evident that the complex viscosity of the PLA is higher than that of PBAT for all of the frequency tested, particularly at the viscosity ratio of $100 \mathrm{rad} / \mathrm{s}$, when PBAT is the dispersed phase, and is equal to 0.25 , and when PBAT is the matrix phase, and is equal to 4 . It is well known that the viscosity ratio has a great influence on the morphology of the blends [39]. In fact, for a viscosity ratio lower than one, the application of high shear determines the formation of the fibrillar morphology of the dispersed phase. Instead, for viscosity ratio higher than one, the dispersed phase has a moderate deformation and keeps its spherical shape [40]. So, a fibrillar morphology is expected when PLA is the matrix phase, and a globular morphology is expected when PBAT is the matrix phase. 
Moreover, the complex viscosity graph shows that the blends had a shear thinning behavior more accentuated than the pure materials, and the increase of PLA content led to an increase of their complex viscosity. Particularly, the PLA/PBAT 80/20 blend not only exhibited a higher viscosity, but, at low frequencies, that viscosity was higher than both PLA and PBAT, suggesting higher interactions of the two polymers at this composition [28].

Figure 2 shows the trend of the storage modulus $\left(\mathrm{G}^{\prime}\right)$ in function of the frequency. The storage modulus of the blends, for high frequencies values, increased as the content of PLA in the blend increased, and instead, at low frequencies, it is higher for all the blends than the pure materials.

For PLA/PBAT 80/20 and 20/80, G' shows a typical shoulder that has been reported for many immiscible blends [28]. This behavior of $G^{\prime}$ is due to the "additional" elastic response originating from the surface tension of the dispersed phase in the continuous matrix. Moreover, a large $\mathrm{G}^{\prime}$ plateau at low frequencies is seen for the blends PLA/PBAT 60/40 and 40/60, reflecting a sort of solid-like behavior. This behavior has been reported in many investigations [41] for immiscible blends that form co-continuous structures, and this is due to extra stresses associated with the shape relaxation of the inter-connective structures [42]. In fact, as reported by Omonov et al. [43], when a continuous network structure is formed, the relaxation times shift to very low frequency values that cannot be observed experimentally, thus they used this criterion to set the composition limits of a co-continuous structure. Therefore, the $40 \mathrm{wt} \%$ and the $60 \mathrm{wt} \%$ of PBAT can be the beginning and the ending points of the co-continuous structure, which are in accordance with the values found in literature that vary from $20 \mathrm{wt} \%$ to $60 \mathrm{wt} \%[28,29,44]$.

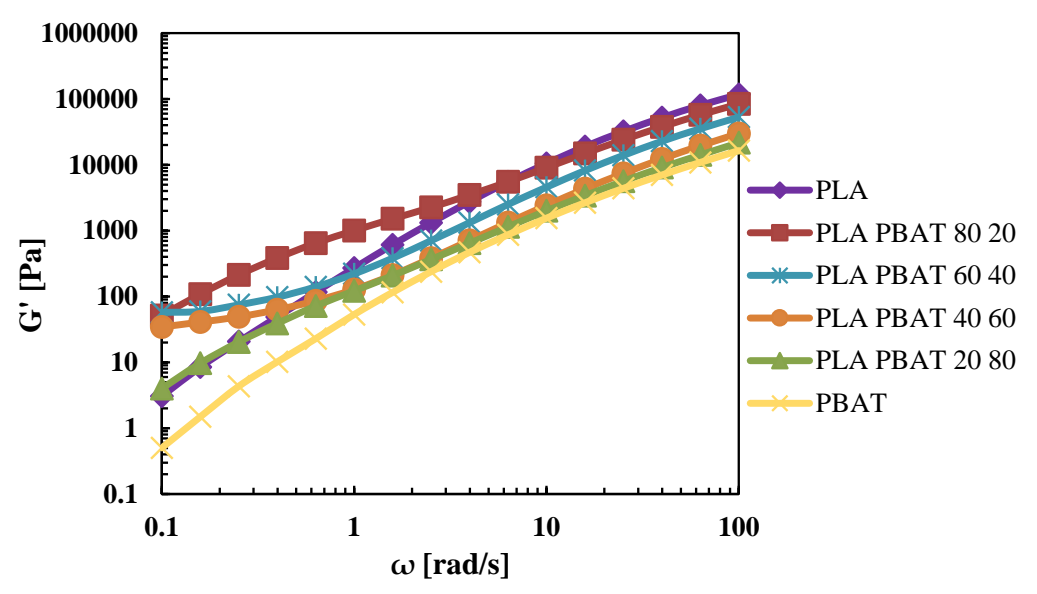

Figure 2. $G^{\prime}$ of the extruded pellets.

\subsection{Thermal Analysis (DSC) of the Films}

All the films were subjected to the same thermal cycle described in the experimental part. The main thermal parameters related to the first heating are shown in the Table 1.

Table 1. Differential Scanning Calorimetry (DSC) results of the 1st Heating scan of the films.

\begin{tabular}{|c|c|c|c|c|c|c|c|c|c|c|c|}
\hline \multicolumn{12}{|c|}{ I Heating } \\
\hline & $\begin{array}{c}\mathrm{T}_{\mathrm{g}} \\
\text { PBAT } \\
{\left[{ }^{\circ} \mathrm{C}\right]}\end{array}$ & $\begin{array}{c}\mathbf{T}_{\mathrm{g}} \\
\text { PLA } \\
{\left[{ }^{\circ} \mathrm{C}\right]}\end{array}$ & $\begin{array}{c}\mathbf{T}_{\mathrm{cc}} \\
{\left[{ }^{\circ} \mathrm{C}\right]}\end{array}$ & $\begin{array}{c}\Delta \mathbf{H}_{\mathrm{cc}} \\
{[\mathrm{J} / \mathrm{g}]}\end{array}$ & $\begin{array}{c}\mathrm{T}_{\mathrm{m} 1} \\
\text { PBAT } \\
{\left[{ }^{\circ} \mathrm{C}\right]}\end{array}$ & $\begin{array}{c}\mathrm{T}_{\mathrm{m} 2} \\
\text { PBAT } \\
{\left[{ }^{\circ} \mathrm{C}\right]}\end{array}$ & $\begin{array}{c}\Delta \mathrm{H}_{\mathrm{m}} \\
\text { PBAT } \\
{[\mathrm{J} / \mathrm{g}]}\end{array}$ & $\begin{array}{c}\mathbf{T}_{\mathrm{m}} \\
\text { PLA } \\
{\left[{ }^{\circ} \mathrm{C}\right]}\end{array}$ & $\begin{array}{l}\Delta \mathrm{H}_{\mathrm{m}} \\
\text { PLA } \\
{[\mathrm{J} / \mathrm{g}]}\end{array}$ & $\begin{array}{c}\mathrm{X}_{\mathrm{c}} \\
\text { PBAT } \\
{[\%]}\end{array}$ & $\begin{array}{c}\mathbf{X}_{\mathrm{c}} \\
\text { PLA } \\
{[\%]}\end{array}$ \\
\hline PLA & 1 & 63.5 & 97.6 & 35.3 & I & I & I & 170.3 & 36.6 & 1 & 1.5 \\
\hline PLA PBAT 8020 & -33.1 & 62.1 & 97.2 & 21.7 & 1 & 1 & 1 & 168.6 & 27.9 & 1 & 8.3 \\
\hline PLA PBAT 6040 & -33.9 & 61.3 & 96.0 & 14.9 & 47.5 & 118.0 & 0.8 & 169.2 & 22.8 & 1.7 & 14.1 \\
\hline PLA PBAT 4060 & -34.1 & 61.5 & 96.4 & 8.0 & 48.2 & 111.8 & 2.3 & 168.8 & 15.3 & 3.3 & 19.4 \\
\hline PLA PBAT 2080 & -35.1 & 63.2 & 95.5 & 1.7 & 48.0 & 112.6 & 7.9 & 167.2 & 6.0 & 8.7 & 22.7 \\
\hline PBAT & -35.4 & / & / & 1 & 48.8 & 110.6 & 17.2 & I & / & 15.1 & l \\
\hline
\end{tabular}


The thermograms of the films of the 1st heating scan are reported in Figure 3.

Thermal properties have a great influence on the mechanical behavior of the films. Particularly, the glass transition temperature $\left(\mathrm{T}_{\mathrm{g}}\right)$ represents the transition point between the glassy and brittle behavior and the ductile behavior [45]. The glass transition temperature of PLA and PBAT are at $63^{\circ} \mathrm{C}$ and $-34{ }^{\circ} \mathrm{C}$, respectively. This means that PLA has a brittle behavior at ambient temperatures (around $25^{\circ} \mathrm{C}$ ), and also for lower temperatures, while PBAT keeps its ductile behavior for temperatures above $-34^{\circ} \mathrm{C}$. Moreover, the thermograms of the first heating of these materials show the presence of one endothermic peak for PLA at $171^{\circ} \mathrm{C}$, and two endothermic peaks for PBAT, at the temperatures of $36^{\circ} \mathrm{C}$ and $107^{\circ} \mathrm{C}$.

The first melting peak, not very intense, can be attributed to the melting of the crystalline phase of the butylene-adipate (BA) fraction [46], while the second melting peak, more intense and widened, is between $70{ }^{\circ} \mathrm{C}$ and $140{ }^{\circ} \mathrm{C}$. All the blends showed two different glass transition temperatures, and this is a further confirmation that PLA and PBAT are not thermodynamically miscible [47]. The presence of PBAT led to a decrease of the cold crystallization temperature $\left(T_{\mathrm{cc}}\right)$ of PLA, indicating that PBAT increases the crystallization rate of PLA, as previously reported $[33,48]$. Moreover, as reported by Deng et al. [29], the crystallinity degree $\left(X_{c}\right)$ of PLA increases with the increase of the PBAT content in the blend. This behavior could be due to the greater mobility of the PLA chains in the presence of the PBAT. On the other hand, the opposite behavior is shown for the degree of crystallinity of PBAT, which decreases as the PLA content in the blend increases. Since PLA has a lower chain flexibility and higher viscosity than PBAT, it restricts the mobility of the PBAT chains, and therefore reduces its crystallinity degree [20].

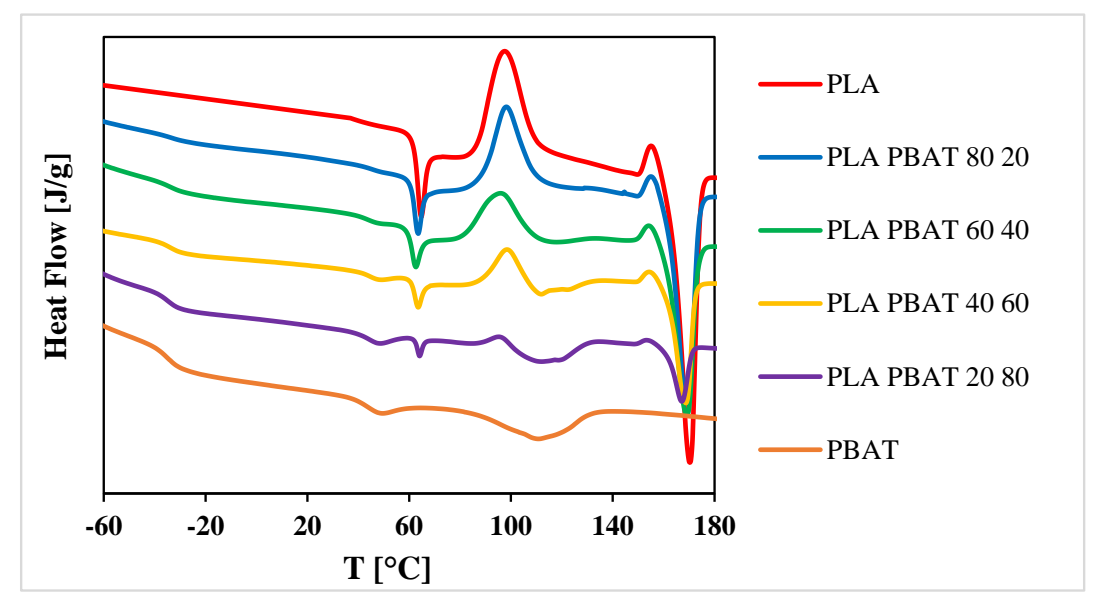

Figure 3. DSC thermograms of the 1st heating scan of the films.

\subsection{FT-IR}

FTIR spectroscopy investigations were performed on the films in order to obtain information on blends morphology, and the results are reported in the Figure 4.

According to Al-Itry et al. [49], the following main characteristic peaks for PLA can be observed: The symmetric stretching vibration of the axial CH groups in saturated hydrocarbons at $2800-3000 \mathrm{~cm}^{-1}$, the intense peak originating from the $\mathrm{C}=\mathrm{O}$ stretching vibrations located at around $1747 \mathrm{~cm}^{-1}$, a weaker band at $1250-1050 \mathrm{~cm}^{-1}$ as a result of the $\mathrm{C}-\mathrm{O}$ carboxyl groups, and two weak peaks at $866.5 \mathrm{~cm}^{-1}$ and $75,464 \mathrm{~cm}^{-1}$ as a result of the $\mathrm{C}-\mathrm{OCC}$ bond stretching and $\mathrm{CO}$ bending, respectively. The functional groups of PBAT can be described as: Peaks at around $3000 \mathrm{~cm}^{-1}$ representing $\mathrm{C}-\mathrm{H}$ stretching in aliphatic and aromatic portions; at around $1710 \mathrm{~cm}^{-1}$ representing carbonyl groups $(\mathrm{C}=\mathrm{O})$ in the ester linkage; at $1267 \mathrm{~cm}^{-1}$ representing $\mathrm{C}-\mathrm{O}$ in the ester linkage; and a sharp peak at $720 \mathrm{~cm}^{-1}$ representing four or more adjacent methylene (-CH2-) groups. Bending peaks of the benzene substitutes are located at wave numbers between 700 and $900 \mathrm{~cm}^{-1}$. In the blends, some peak shifts were detected: The peak 
of the PLA carbonyl group shifts as the PBAT content increased from $1747 \mathrm{~cm}^{-1}$ to $1753 \mathrm{~cm}^{-1}$ in the PLA/PBAT 60/40 blend; the peak of the carbonyl group of PBAT moved as the PLA increases from $1710 \mathrm{~cm}^{-1}$ to $1714 \mathrm{~cm}^{-1}$ in the PLA/PBAT 60/40 blend; the peak at $866.5 \mathrm{~cm}^{-1}$ of PLA C-OCC moved progressively to values between 870 and $872 \mathrm{~cm}^{-1}$ as the content of PBAT in the blend increased, and the peak relative to the $\mathrm{CO}$ bending moved up to $750 \mathrm{~cm}^{-1}$ in the blend PLA/PBAT 20/80. These shifts indicate that these polymers, even though they are immiscible, have some interactions, and a certain degree of compatibility.

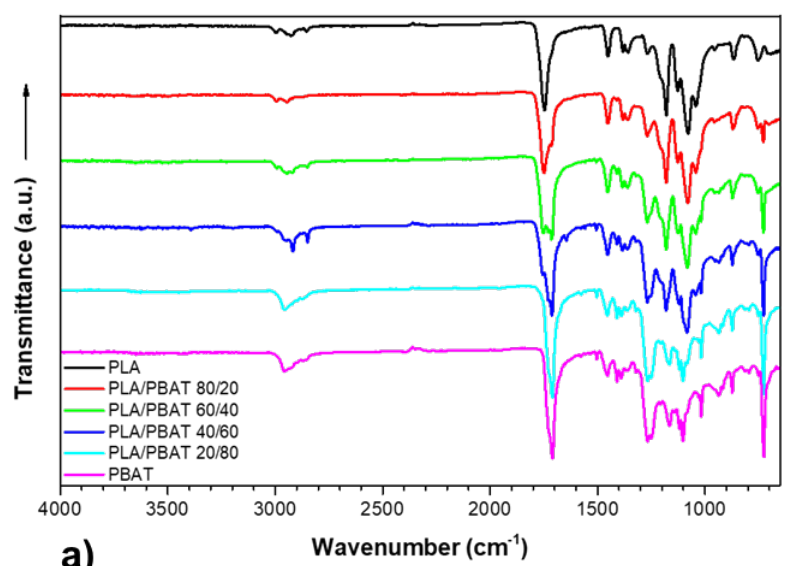

a)

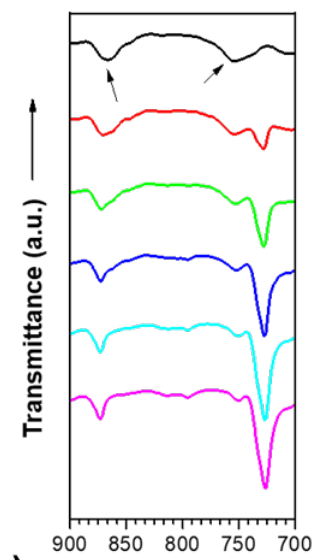

b)

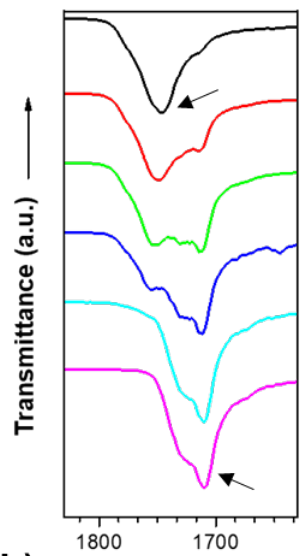

C) Wavenumber $\left(\mathrm{cm}^{-1}\right)$

Figure 4. Fourier transform infrared spectroscopy (FTIR) spectra of the films: (a) in the full x-axis scale (b) zoom of the carbonyl bonds (c) zoom of the C-OCC and $\mathrm{CO}$ bonds.

\subsection{Morphological Characterization}

Figure 5 gives the FESEM images of the fracture surface of the films for the neat polymers and their blends. PLA and PBAT show homogeneous fracture surfaces. On the contrary, all the blends exhibit a typical two-phase structure characterized by the presence of voids and inclusions of variable shape and dimension. Different morphologies of the dispersed phase can be observed for these blends. When PBAT was the dispersed phase, the blends showed an elongated fibrous morphology, yet instead when PBAT became the matrix phase, the morphology turned into globular, in accordance with their viscosity ratios. Particularly, the blend with the $80 \%$ of PLA showed an elongated dispersed phase with thin fibrils that confirms the higher interactions of the two polymers in this composition supposed in the rheological analysis. Moreover, the blends with a content of the dispersed phase equal to $40 \%$ showed bigger inclusions than the other blends.

In fact, higher concentrations of the dispersed phase can lead to higher coalescence, and so to bigger dimensions of the aggregates [44]. However, discrete domains that are not part of a network 
structure can be observed for both the blends with a dispersed phase content of $40 \mathrm{wt} \%$, suggesting that the "fully co-continuous structure" could be formed in a composition between this range.

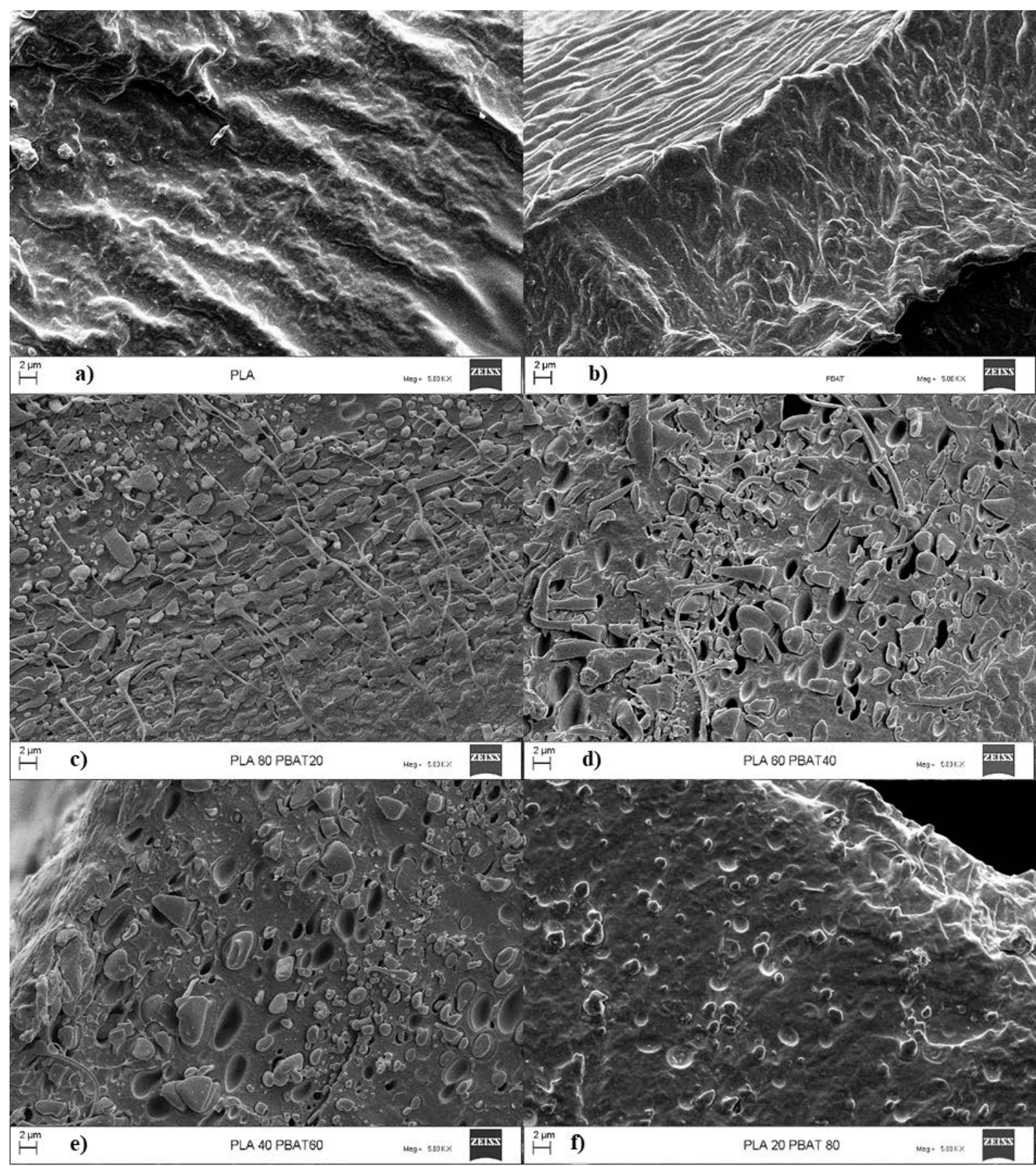

Figure 5. Field emission scanning electron microscope (FESEM) images of: (a) neat poly(lactide) (PLA), (b) neat poly(butylene-adipate-co-terephthalate) (PBAT), (c) PLA PBAT 80/20, (d) PLA PBAT 60/40 (e) PLA PBAT 40/60, (f) PLA PBAT 20/80.

\subsection{Barrier Properties}

Oxygen and moisture barrier properties are among the most important issues to be considered in materials intended to be used in food packaging, since their presence in some cases may lead to detrimental changes in quality that result in a decrease of the food shelf-life. In Table 2 the permeability coefficient to oxygen and water vapor are reported. 
Table 2. Oxygen and water vapor permeability coefficients of the films.

\begin{tabular}{ccc}
\hline & $\mathbf{P ~ O}_{\mathbf{2}}\left[\mathbf{c m}^{\mathbf{3}} \cdot \mathbf{m m} / \mathbf{m}^{\mathbf{2}} \cdot \mathbf{d} \cdot \mathbf{b a r}\right]$ & $\mathbf{P ~ H}_{\mathbf{2}} \mathbf{O}\left[\mathbf{g} \cdot \mathbf{m m} /\left(\mathbf{d} \cdot \mathbf{m}^{\mathbf{2}}\right)\right]$ \\
\hline PLA & 33.4 & 1.3 \\
PLA PBAT 80 20 & 40.9 & 1.4 \\
PLA PBAT 60 40 & 50.3 & 2.8 \\
PLA PBAT 40 60 & 61.9 & 2.9 \\
PLA PBAT 20 80 & 71.8 & 3.0 \\
PBAT & 84.0 & 3.1 \\
\hline
\end{tabular}

From the reported table it is clear that PBAT showed significant lower barrier properties to both oxygen and water vapor than neat PLA; in fact, from the above-reported results, it is clear that adding PBAT to PLA results in an increase of the coefficient of permeability, as reported in literature $[23,33]$. This could be related to the different glass transition temperatures of these polymers. PLA at $23^{\circ} \mathrm{C}$ is in the glassy state, which means a lower fraction of free volume between the polymer chains, and a reduced mobility compared to PBAT that has a Tg under $23^{\circ} \mathrm{C}$. These factors greatly influence the permeability of gas molecules, whose permeability is facilitated with high chains mobility and free volume fractions.

Moreover, for polymer blends, it is useful to predict the macroscopic properties, thus different models were applied in order to find the best fitting for the oxygen permeability of PLA/PBAT blends. In the Maxwell equations, the two different polymers are replaced with two bars consisting of a rubbery and a glassy phase.

In the parallel model, the two bars are connected in parallel, and in the series model they are connected in series. These models represent the highest and lowest limits for the permeability coefficient of a polymeric blend. The Maxwell series and parallel model $[49,50]$ are respectively:

$$
\begin{gathered}
\mathrm{P}_{\mathrm{b}}=\mathrm{P}_{1} \cdot \mathrm{P}_{2} /\left(\varphi_{1} \cdot \mathrm{P}_{2}+\varphi_{2} \cdot \mathrm{P}_{1}\right) \\
\mathrm{P}_{\mathrm{b}}=\varphi_{1} \cdot \mathrm{P}_{1}+\varphi_{2} \cdot \mathrm{P}_{2}
\end{gathered}
$$

where $\mathrm{Pb}$ is the permeability of the blend, $\mathrm{P}_{1}$, and $\mathrm{P}_{2}$ are the permeabilities of the respective phases, with $\varphi_{1}$ and $\varphi_{2}$, being the corresponding volume fractions.

Robeson's equation describes the effect of a spherical filler on the overall composite permeability [51]. The equation is reported below:

$$
\mathrm{Pb}=\mathrm{Pm} \cdot[\mathrm{Pd}+2 \mathrm{Pm}-2 \cdot \varphi \mathrm{d} \cdot(\mathrm{Pm}-\mathrm{Pd})] /[\mathrm{Pd}+2 \mathrm{Pm}+\varphi \mathrm{d} \cdot(\mathrm{Pm}-\mathrm{Pd})]
$$

where $\mathrm{Pb}$ is the permeability of the blend, $\mathrm{Pm}$ is the permeability of the matrix, $\mathrm{Pd}$ is the permeability of the disperse phase, and $\varphi d$ is the volume fraction of dispersed phase.

Figure 6 shows that the experimental values of oxygen permeability are between the Maxwell series and the parallel equations. The curve that fits best the experimental results is the Robeson equation, particularly for the PLA/PBAT 80/20 and 20/80 samples, likely due to dispersed morphology of these compositions. Thus, the Robeson equation could be applied for the prediction of the oxygen permeability coefficient of the PLA/PBAT blends. 


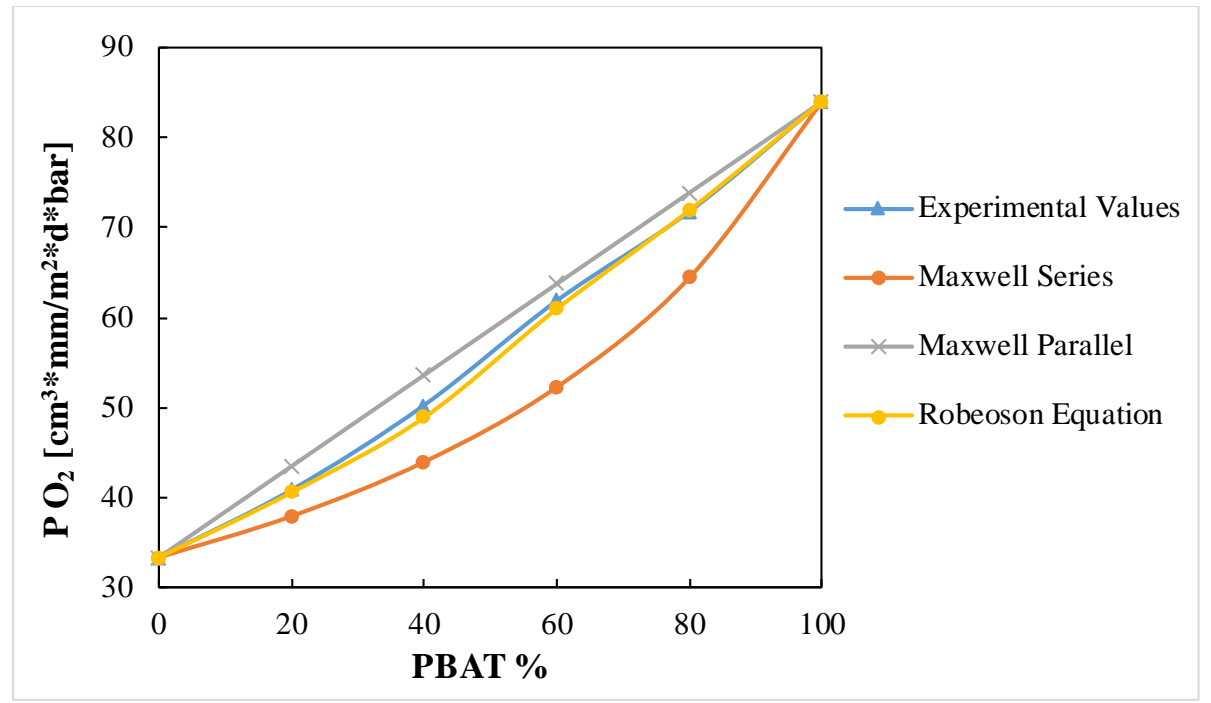

Figure 6. Oxygen Permeability in function of the blends' composition.

\subsection{Mechanical Properties}

Results of the tensile tests performed at ambient temperature are reported in Figure 7 and in Table 3.

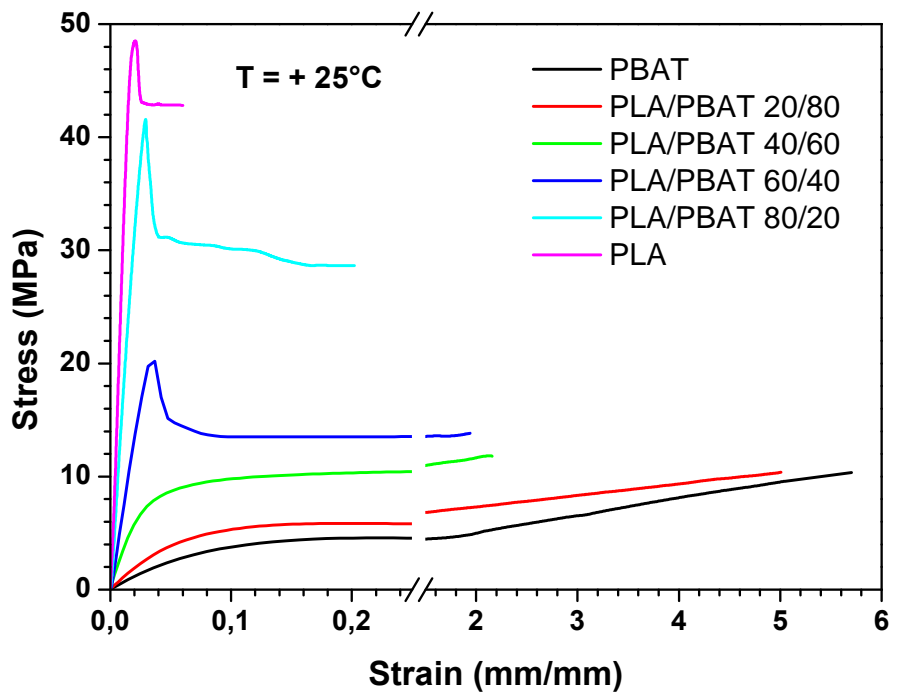

Figure 7. Tensile stress-strain curves, obtained at $25^{\circ} \mathrm{C}$, for all the films.

Table 3. Tensile properties of the films at $25^{\circ} \mathrm{C}$.

\begin{tabular}{cccc}
\hline \multicolumn{4}{c}{ Mechanical Properties at Ambient Temperature } \\
\hline Blend & E (MPa) & $\varepsilon \mathbf{b}(\mathbf{\%})$ & $\boldsymbol{\sigma y} \mathbf{~ ( M P a ) ~}$ \\
\hline PLA & $2411.0 \pm 164.3$ & $6.7 \pm 1.2$ & $45.3 \pm 5.4$ \\
PLA PBAT 80 20 & $1432.1 \pm 119.7$ & $15.4 \pm 3.8$ & $39.1 \pm 2.5$ \\
PLA PBAT 60 40 & $819.6 \pm 73.1$ & $183.0 \pm 20.1$ & $22.1 \pm 2.3$ \\
PLA PBAT 40 60 & $288.0 \pm 27.4$ & $220.8 \pm 12.9$ & $9.7 \pm 1.2$ \\
PLA PBAT 20 80 & $110.9 \pm 6.6$ & $531.9 \pm 43.2$ & $6.1 \pm 0.7$ \\
PBAT & $69.1 \pm 5.0$ & $581.1 \pm 119.9$ & $5.1 \pm 0.8$ \\
\hline
\end{tabular}

From Figure 7, it is evident that PLA and PBAT have an opposite behavior: the first is rigid and brittle, and the second is flexible and tough. Moreover, the blend films exhibit behavior intermediate 
between that of the neat components, showing a progressive change from fragility to ductility as the PBAT content grows.

In particular, with respect to the neat PLA film, the blend at the highest PBAT loading has a decrease of the elastic modulus (E) and yield stress ( $\sigma \mathrm{y})$ of an order of magnitude, and an increase of the elongation at break $(\varepsilon b)$ of two orders of magnitude.

Similar trends in the mechanical behavior of PLA/PBAT blends are reported in the literature also by others [32,33]. On the contrary, Deng et al. [29], reporting on a series of melt-blended PLA/PBAT, found a drop of the elongation at break for a PBAT mass content between $50 \%$ and $60 \%$.

Moreover, as for the oxygen permeability, it can be useful to predict the mechanical properties of a polymeric blend. Particularly, the elastic modulus is strongly dependent on the blend morphology and composition, and could be useful to assess the miscibility in polymers blends [52]. The Parallel and the Series Model [53] represent the highest and the lowest bound of the modulus of a polymer system, respectively:

$$
\begin{gathered}
E_{b}=E_{1} \varphi_{1}+E_{2} \varphi_{2} \\
1 / E_{b}=1 /\left(E_{1} \varphi_{1}+E_{2} \varphi_{2}\right)
\end{gathered}
$$

Another model is the Davies Equation [54], which describes the elastic modulus behavior for macroscopically homogeneous and isotropic blends, thus it is valid for co-continuous systems:

$$
\mathrm{E}_{\mathrm{b}}^{1 / 5}=\mathrm{E}_{1}^{1 / 5} \varphi_{1}+\mathrm{E}_{2}{ }^{1 / 5} \varphi_{2}
$$

The experimental result of the modulus and the theoretical predictions of the above-reported equations are given in Figure 8.

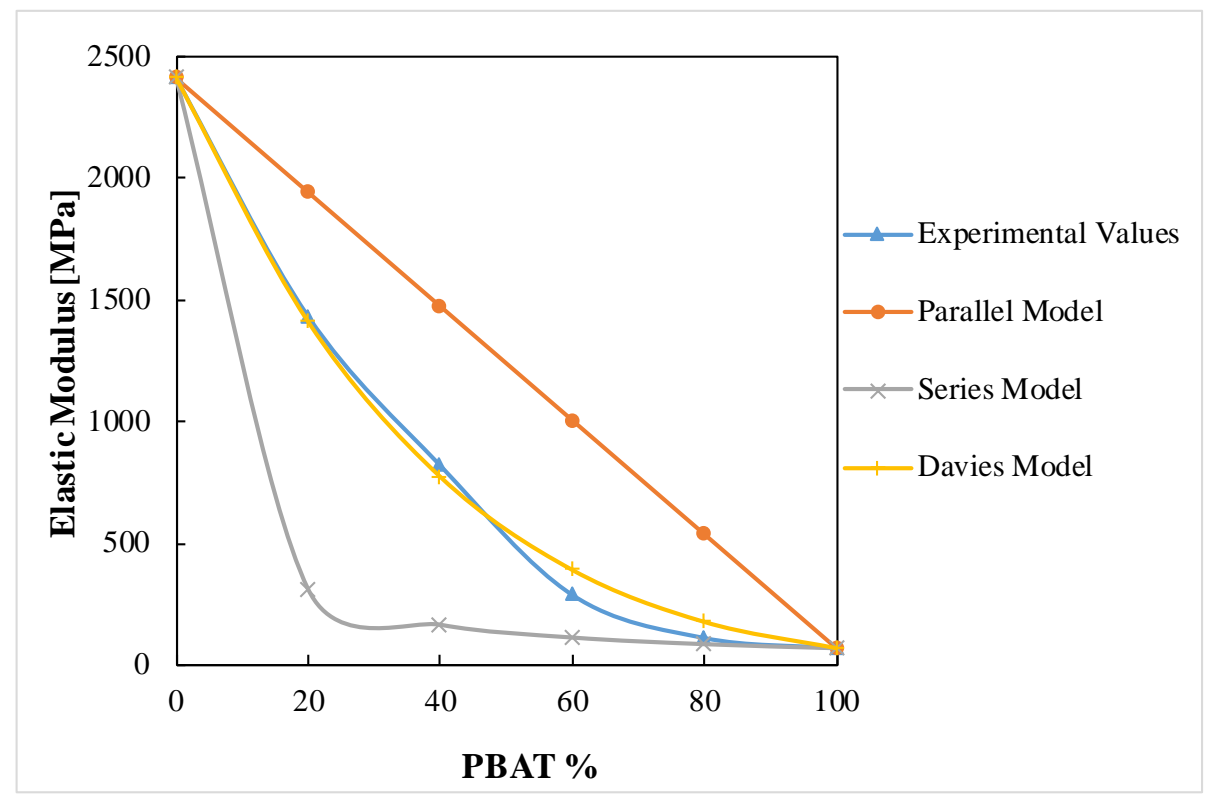

Figure 8. Elastic modulus in function of the blends' composition.

From Figure 8, it can be seen that the experimental values of the elastic modulus are between the highest and lowest limits of the parallel and series models. However, the model that fits best the experimental values is the Davies ones. Particularly, at $40 \%$, there is a change in slope of the experimental values' curve that intersects the Davies Equation in a composition between $40 \%$ and $60 \%$ of PBAT, as a further confirmation of the possible formation of a co-continuous phase in this range. Moreover, the elastic modulus of the blends with a PBAT content of $20 \%$ is the closest to the parallel model, a sign of the highest level of interactions of the two polymers in this composition, as revealed by the rheological and morphological analysis. 
Few works in literature deal with the application of literature models to the mechanical properties of PLA/PBAT blends. Deng et al. [29] also found a similar trend with the experimental values of the elastic modulus comprised between the series and the parallel model, while Gigante et al. [36] found that the experimental values, up to a PBAT content of $25 \%$, followed the Parallel model.

From the analysis of the mechanical properties at ambient temperature, it is evident that the most ductile blends are those in which PBAT is the matrix phase (i.e., PLA/PBAT 40/60, PLA/PBAT 20/80 and PBAT). Therefore, the mechanical behavior of these blends was determined also at $4{ }^{\circ} \mathrm{C}$, which is the typical fridge temperature, and at $-25^{\circ} \mathrm{C}$, which is the typical temperature of the industrial freezer, in order to test their suitability as chilled and frozen food packaging materials. Figures 9 and 10 show the stress-strain curves obtained at $4{ }^{\circ} \mathrm{C}$ and $-25^{\circ} \mathrm{C}$, respectively, whereas Figures 11-13 compare respectively the elastic modulus, the stress at yield, and the elongation at break for the PLA/PBAT 40/60, PLA/PBAT 20/80 and PBAT films at the three test temperatures.

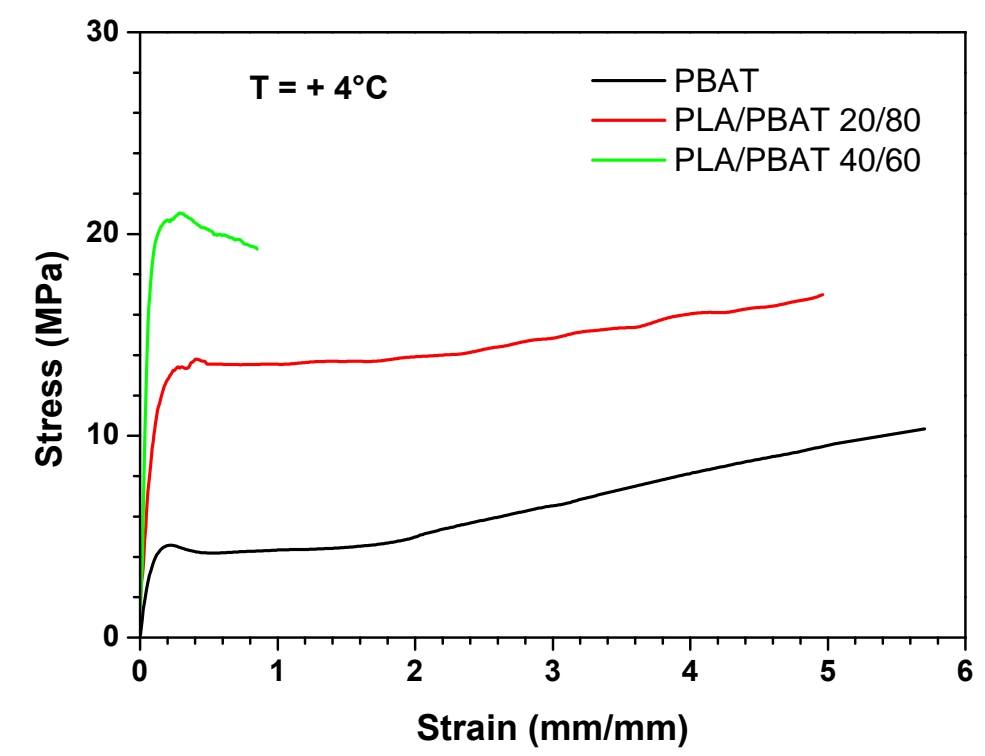

Figure 9. Stress-strain curves at $+4{ }^{\circ} \mathrm{C}$ for PBAT, PLA/PBAT 20/80 and PLA/PBAT 40/60 films.

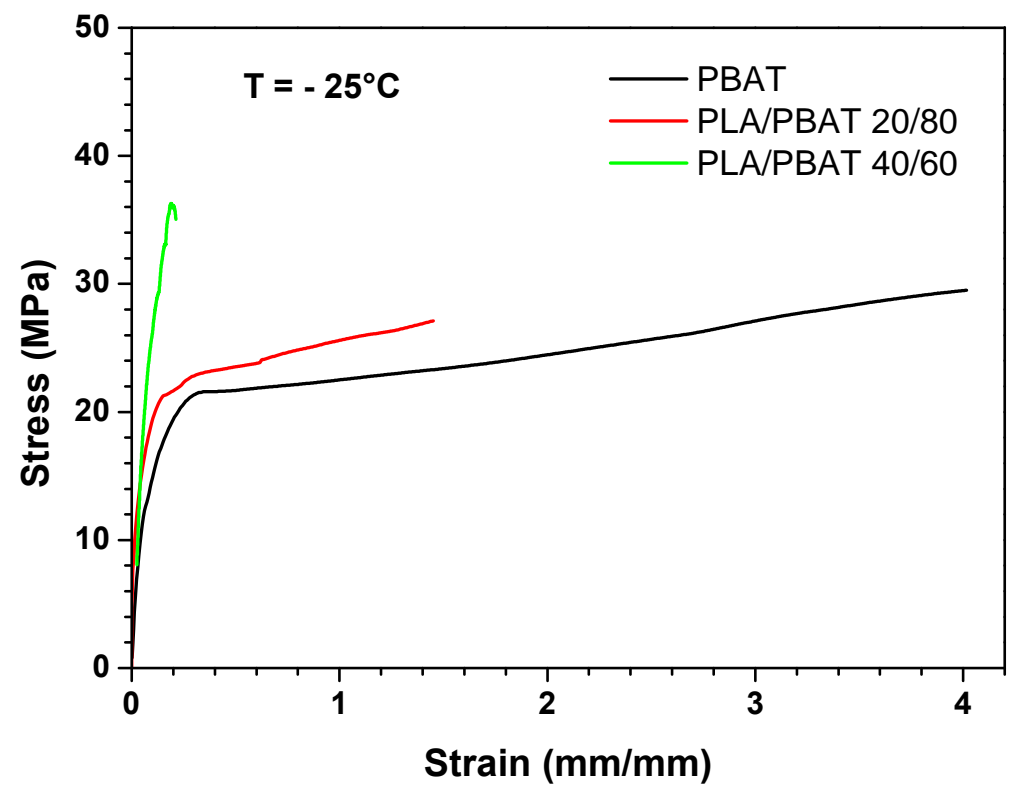

Figure 10. Stress-strain curves at $-25^{\circ} \mathrm{C}$ for PBAT, PLA/PBAT 20/80 and PLA/PBAT 40/60 films. 


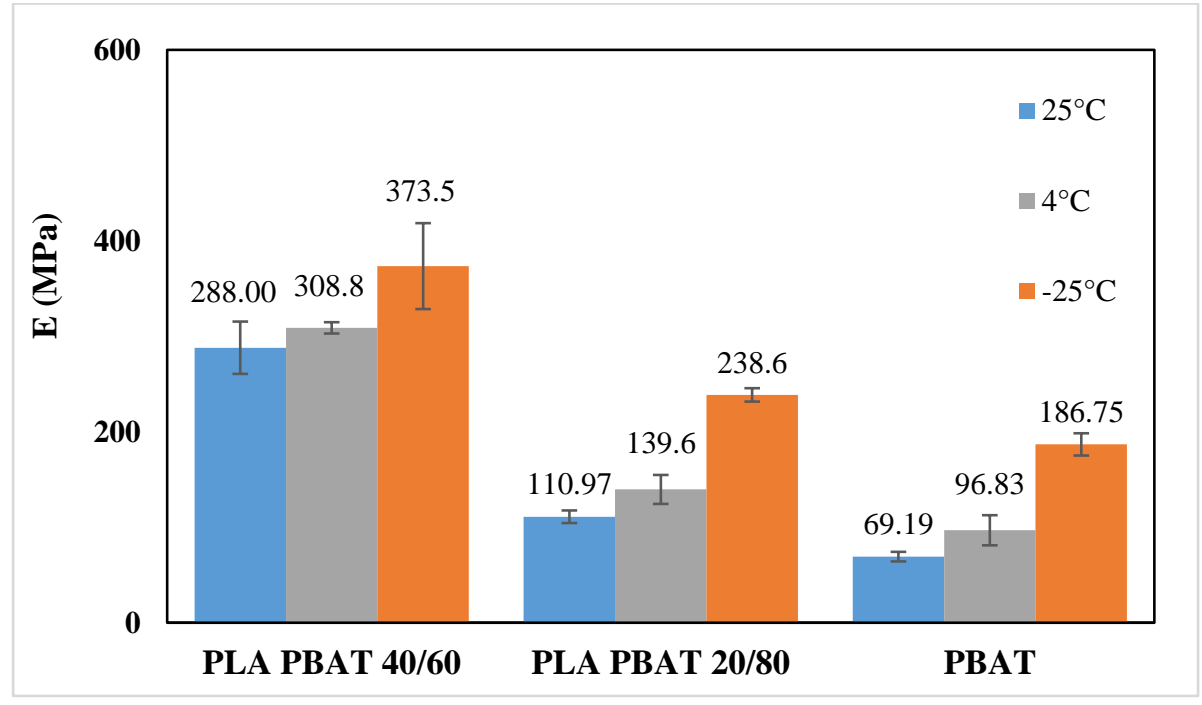

Figure 11. Comparison of elastic modulus at different temperatures.

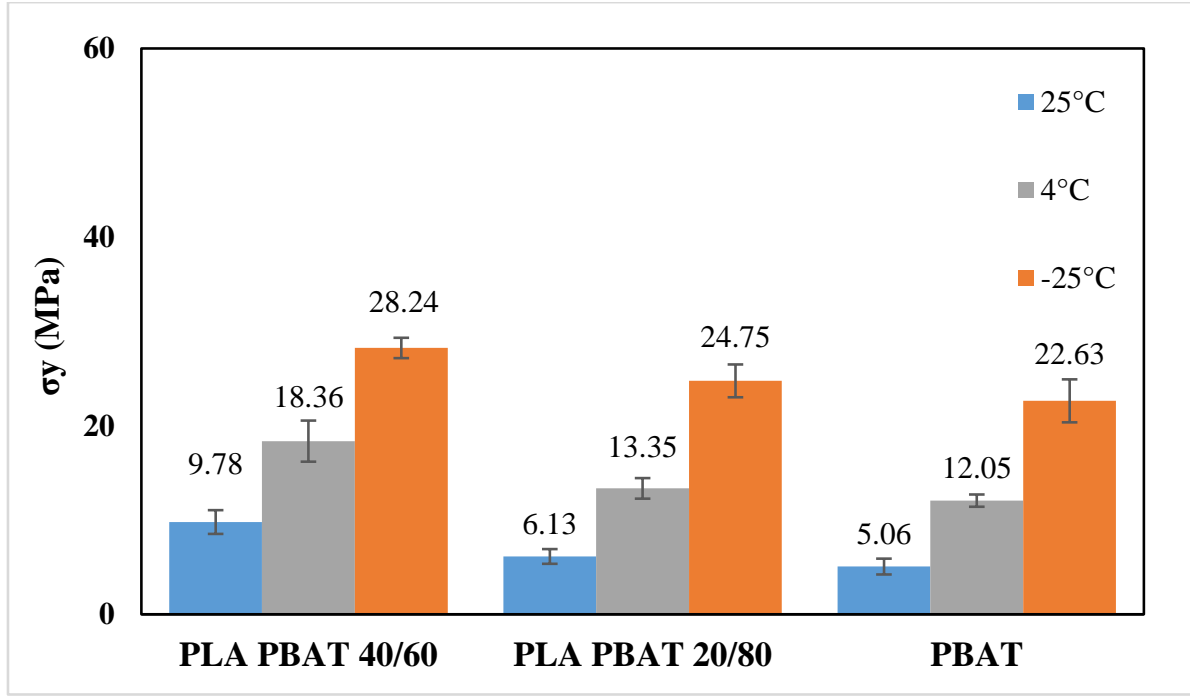

Figure 12. Comparison of yield at stress at different temperatures.

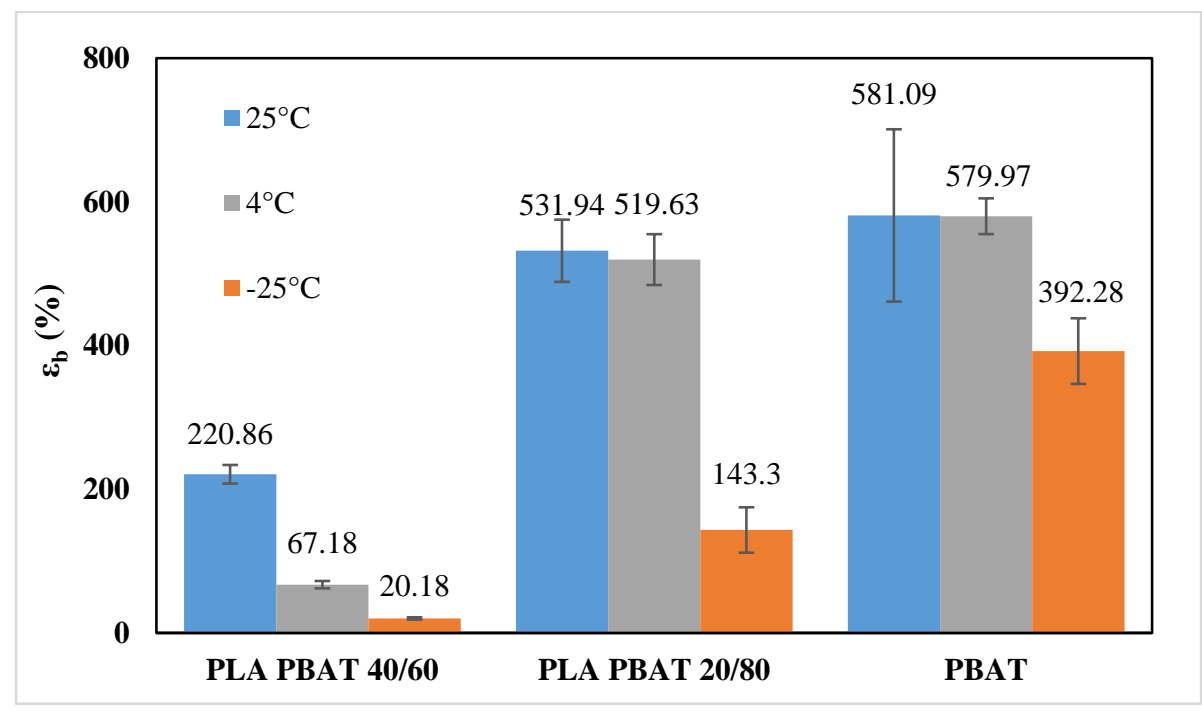

Figure 13. Comparison of the elongation at break at different temperatures. 
From these graphs it is clear that the decrease in temperature caused, for all the tested blends, an increase in both elastic modulus and yield stress, and a decrease in the elongation at break. These results are expected, because the decrease in temperature reduces the polymer chain flexibility, and increases the stiffness of the material. However, this variation had a different extent in the function of the blend's composition. In fact, the increase of the elastic modulus was more accentuated as the content of PBAT in the blend increased, varying from the 30\% for PLA/PBAT 40/60 to 170\% for pure PBAT (at $-25^{\circ} \mathrm{C}$ ). This can be explained by the fact that, since the glass transition temperature of PBAT is close to $-25^{\circ} \mathrm{C}$, the Elastic modulus has a higher dependence upon the temperature compared to PLA, whose elastic modulus in this temperature range $\left(-25^{\circ} \mathrm{C}\right.$ to $\left.25^{\circ} \mathrm{C}\right)$ is almost constant. As regards the ductility, the effect of the composition was the opposite compared to the elastic modulus. In fact, the decrease in the elongation at break was more evident as the content of PLA increased, ranging from the $90 \%$ PLA/PBAT $40 / 60$ to $30 \%$ for pure PBAT (at $-25^{\circ} \mathrm{C}$ ). Particularly, the blend with a PLA content equal to $40 \%$, at $-25{ }^{\circ} \mathrm{C}$ turned its failure mode from ductile to brittle. This could be due the fact that, at all of the tested temperatures, PLA is in the glassy state, and instead PBAT is the rubbery state, so its ductility is less sensitive than PLA to the temperature decrease. In conclusion, both PLA/PBAT 40/60 and 20/80 could be good candidates for chilled food applications, showing at $4{ }^{\circ} \mathrm{C}$ a good compromise between stiffness and ductility. At $-25^{\circ} \mathrm{C}$, the failure mode of PLA/PBAT $60 / 40$ changed from ductile at ambient temperatures to brittle, while the PLA/PBAT 20/80 kept its ductile failure mode, revealing that it is the best candidate for frozen food applications.

\section{Conclusions}

In this study, blown films of PLA and PBAT in a wide range of compositions (100/0, 80/20, 60/40, $40 / 60$ 20/80 0/100 by weight) were produced using a lab-scale film blowing plant, and were characterized in terms of microstructure and functional properties in order to determine their suitability as food packaging materials for room and low temperature (chilling and freezing) storage conditions.

The two polymers, although immiscible in all the compositions tested, proved to have some interactions, as inferred by infrared spectroscopy. This causes that the microstructure of the blend films depends strongly on their composition. In particular, the presence of PBAT raises the crystallinity degree of PLA (from $8 \%$ of pure PLA, to $22 \%$ of the PLA/PBAT 20/80 blend), while the presence of PLA had the opposite effect on PBAT (from $15 \%$ of pure PBAT to $2 \%$ of the PLA/PBAT $80 / 20$ blend). In terms of performances, the barrier properties to oxygen and water vapor, while it decreased with the increase of PBAT content according to the Robeson equation, remained in the same order of magnitude for all the compositions; $\mathrm{P} \mathrm{O}_{2}$ varied from 33.4 to $84\left(\mathrm{~cm}^{3} \cdot \mathrm{mm}\right) /\left(\mathrm{m}^{2} \cdot \mathrm{d} \cdot\right.$ bar $)$ and $\mathrm{P}_{2} \mathrm{O}$ from 1.3 to $3.1(\mathrm{~g} \cdot \mathrm{mm}) /\left(\mathrm{d} \cdot \mathrm{m}^{2}\right)$. Moreover, the ductility increases and the stiffness decreases, according to the Davies model, as the PBAT content in the blends becomes progressively higher, at all test temperatures. However, at fixed blend composition, the ductility decreased, and the stiffness increased the lower is the temperature.

On this basis, among the considered blown films, the following two blends were selected as best candidates as packaging materials for food requiring low storage temperatures, thanks to a balance of mechanical properties in the typical range of conventional polymer systems used for this kind of applications. In particular, the blend with a PBAT content of $60 \%$ proved to be adequate for chilled foods: in fact, at $4{ }^{\circ} \mathrm{C}$ (which is the typical fridge temperature) it had an elastic modulus equal to 308 $\mathrm{MPa}$, and elongation at break of $67 \%$. Instead, the blend with a PBAT content of $80 \%$ was adequate for frozen foods: in fact, at $-25^{\circ} \mathrm{C}$ (which is the temperature of an industrial freezer) it had an elastic modulus of $238 \mathrm{MPa}$ and elongation at break equal to $143 \%$.

Author Contributions: Conceptualization, L.I.; Data curation, A.P. and L.D.M.; Formal analysis, L.D.M. and M.R.N.; Funding acquisition, L.I.; Investigation, A.P. and M.R.N.; Supervision, P.S. and L.I.; Writing-original draft, A.P.; Writing-review and editing, P.S. and L.I. All authors have read and agreed to the published version of the manuscript.

Funding: This research received no external funding. 
Conflicts of Interest: The authors declare no conflicts of interest.

\section{References}

1. Krishnan, S.; Pandey, P.; Mohanty, S.; Nayak, S.K. Toughening of Polylactic Acid: An Overview of Research Progress. Polym. Plast. Technol. Eng. 2016, 55, 1623-1652. [CrossRef]

2. Plastics Europe. Plastic-the Facts 2019: An Analysis of European Plastics Production, Demand and Waste Data. 2019. Available online: https://www.plasticseurope.org/en/resources/publications/1804-plastics-facts-2019 (accessed on 18 March 2020).

3. Dilkes-Hoffman, L.S.; Lane, J.L.; Grant, T.; Pratt, S.; Lant, P.A.; Laycock, B. Environmental impact of biodegradable food packaging whenconsidering food waste. J. Clean. Prod. 2018, 180, 325-334. [CrossRef]

4. Lacks, D.; Rutledge, G. Simulation of the Temperature Dependence of Mechanical Properties of Polyethylene. J. Phys. Chem. 1994, 98, 1222-1231. [CrossRef]

5. Jordan, J.L.; Casem, D.T.; Bradley, J.M.; Dwivedi, A.K.; Brown, E.N.; Jordan, C.W. Mechanical Properties of Low Density Polyethylene. J. Dyn. Behav. Mater. 2016, 2, 411-420. [CrossRef]

6. Alcock, B.; Cabrera, N.O.; Barkoula, N.-M.; Reynolds, C.T.; Govaert, L.E.; Peijs, T. The effect of temperature and strain rate on the mechanical properties of highly oriented polypropylene tapes and all-polypropylene composites. Compos. Sci. Technol. 2007, 67, 2061-2070. [CrossRef]

7. Mrkić, S.; Galić, K.; Ivanković, M. Effect of Temperature and Mechanical Stress on Barrier Properties of Polymeric Films Used for Food Packaging. J. Plast. Film Sheet. 2007, 23, 239-256. [CrossRef]

8. Farah, S.; Anderson, D.G.; Langer, R. Physical and mechanical properties of PLA, and their functions in widespread applications-A comprehensive review. Adv. Drug Deliv. Rev. 2016, 107, 367-392. [CrossRef]

9. Scarfato, P.; Di Maio, L.; Milana, M.R.; Giamberardini, S.; Denaro, M.; Incarnato, L. Performance properties, lactic acid specific migration and swelling by simulant of biodegradable poly(lactic acid)/nanoclay multilayer films for food packaging. Food Addit. Contam. A 2017, 34, 1730-1742. [CrossRef]

10. Scarfato, P.; Avallone, E.; Galdi, M.R.; Di Maio, L.; Incarnato, L. Preparation, characterization, and oxygen scavenging capacity of biodegradable $\alpha$-tocopherol/PLA microparticles for active food packaging applications. Polym. Compos. 2017, 38, 981-986. [CrossRef]

11. Di Maio, L.; Garofalo, E.; Scarfato, P.; Incarnato, L. Effect of Polymer/Organoclay Composition on Morphology and Rheological Properties of Polylactide Nanocomposites. Polym. Compos. 2015, 36, 1135-1144. [CrossRef]

12. Clarkson, C.M.; El Awad Azrak, S.M.; Chowdhury, R.; Nandy Shuvo, S.; Snyder, J.; Schueneman, G.; Ortalan, V.; Youngblood, J.P. Melt Spinning of Cellulose Nanofibril/Polylactic Acid (CNF/PLA) Composite Fibers for High Stiffness. ACS Appl. Polym. Mater. 2019, 1-2, 160-168. [CrossRef]

13. Rubio-Lòpez, A.; Olmedo, A.; Díaz-Álvarez, A.; Santiuste, C. Manufacture of compression moulded PLA based biocomposites: A parametric study. Compos. Struct. 2015, 131, 995-1000. [CrossRef]

14. Karkhanis, S.S.; Stark, N.M.; Sabo, R.C.; Matuana, L.M. Blown film extrusion of poly(lactic acid) without melt strength enhancers. J. Appl. Polym. Sci. 2017, 134, 45212-452229. [CrossRef]

15. Coppola, B.; Cappetti, N.; Di Maio, L.; Scarfato, P.; Incarnato, L. 3D Printing of PLA/clay Nanocomposites: Influence of Printing Temperature on Printed Samples Properties. Materials 2018, 11, 1947. [CrossRef] [PubMed]

16. Bitinis, N.; Verdejo, R.; Cassagnau, P.; Lopez-Manchado, M.A. Structure and properties of polylactide/natural rubber blends. Mater. Chem. Phys. 2011, 129, 823-831. [CrossRef]

17. Zhang, C.; Li, W.; Zhu, B.; Chen, H.; Chi, H.; Li, L.; Qin, Y.; Xue, J. The Quality Evaluation of Postharvest Strawberries Stored in Nano-Ag Packages at Refrigeration Temperature. Polymers 2018, 10, 894. [CrossRef]

18. Wang, S.; Daelemans, L.; Fiorio, R.; Gou, M.; D’hooge, D.R.; De Clerck, K.; Cardon, L. Improving Mechanical Properties for Extrusion-Based Additive Manufacturing of Poly(Lactic Acid) by Annealing and Blending with Poly(3-Hydroxybutyrate). Polymers 2019, 11, 1529. [CrossRef]

19. García-Masabet, V.; Santana Pérez, O.; Cailloux, J.; Abt, T.; Sánchez-Soto, M.; Carrasco, F.; Maspoch, M.L. PLA/PA Bio-Blends: Induced Morphology by Extrusion. Polymers 2020, 12, 10. [CrossRef]

20. Arruda, L.C.; Magaton, M.; Suman Bretas, R.E.; Ueki, M.M. Influence of chain extender on mechanical, thermal and morphological properties of blown films of PLA/PBAT blends. Polym. Test. 2015, 43, $27-37$. [CrossRef] 
21. Chiu, H.-T.; Huang, S.-Y.; Chen, Y.-F.; Kuo, M.-T.; Chiang, T.-Y.; Chang, C.-Y.; Wang, Y.-H. Heat Treatment Effects on the Mechanical Properties and Morphologies of Poly (Lactic Acid)/Poly (Butylene Adipate-co-terephthalate) Blends. Int. J. Polym. Sci. 2013, 2013, 951696. [CrossRef]

22. Gu, S.-Y.; Zhang, K.; Ren, J.; Zhan, H. Melt rheology of polylactide/poly(butylene adipate-co-terephthalate) blends. Carbohydr. Polym. 2008, 74, 79-85. [CrossRef]

23. Wang, L.F.; Rhim, J.W.; Hong, S.-I. Preparation of poly(lactide)/poly(butylene adipate-co-terephthalate) blend films using a solvent casting method and their food packaging application. LWT-Food Sci. Technol. 2016, 68, 454-461. [CrossRef]

24. Al-Itry, R.; Lamnawar, K.; Maazouz, A. Biopolymer Blends Based on Poly (lactic acid): Shear and Elongation Rheology/Structure/Blowing Process Relationships. Polymers 2015, 7, 939-962. [CrossRef]

25. Rapisarda, M.; La Mantia, F.P.; Ceraulo, M.; Mistretta, M.C.; Giuffrè, C.; Pellegrino, R.; Valenti, G.; Rizzarelli, P. Photo-Oxidative and Soil Burial Degradation of Irrigation Tubes Based on Biodegradable Polymer Blends. Polymers 2019, 11, 1489. [CrossRef] [PubMed]

26. Wu, H.; Hao, M. Strengthening and Toughening of Polylactide/Sisal Fiber Biocomposites via in-situ Reaction with Epoxy-Functionalized Oligomer and Poly (butylene-adipate-terephthalate). Polymers 2019, 11, 1747. [CrossRef] [PubMed]

27. Liu, T.Y.; Lin, W.C.; Yang, M.C.; Chen, S.Y. Miscibility, thermal characterization and crystallization of poly(l-lactide) and poly(tetramethylene adipate-co-terephthalate) blend membranes. Polymer 2005, 46, 12586-12594. [CrossRef]

28. Li, K.; Peng, J.; Turng, L.S.; Huang, H.-X. Dynamic Rheological Behavior and Morphology of Polylactide/Poly(butylenes adipate-co-terephthalate) Blends with Various Composition Ratios. Adv. Polym. Technol. 2011, 30, 151-157. [CrossRef]

29. Deng, Y.; Yu, C.; Wongwiwattana, P.; Thomas, N.L. Optimising Ductility of Poly(Lactic Acid)/Poly(Butylene Adipate-co-Terephthalate) Blends Through Co-continuous Phase Morphology. J. Polym. Environ. 2018, 26, 3802-3816. [CrossRef]

30. Hongdilokkul, P.; Keeratipinit, K.; Chawthai, S.; Hararak, B.; Seadan, M.; Suttiruengwong, S. A study on properties of PLA/PBAT from blown film process. IOP Conf. Ser. Mater. Sci. Eng. 2015, 87, 012112. [CrossRef]

31. Xiao, H.; Lu, W.; Yeh, J.-T. Crystallization behavior of fully biodegradable poly(lactic acid)/poly(butylene adipate-co-terephthalate) blends. J. Appl. Polym. Sci. 2009, 112, 3754-3763. [CrossRef]

32. Wang, X.; Peng, S.; Chen, H.; Yu, X.; Zhao, X. Mechanical properties, rheological behaviors, and phase morphologies of high-toughness PLA/PBAT blends by in-situ reactive compatibilization. Compos. Part B-Eng. 2019, 173, 107028. [CrossRef]

33. Li, X.; Ai, X.; Pan, H.; Yang, J.; Gao, G.; Zhang, H.; Yang, H.; Dong, L. The morphological, mechanical, rheological, and thermal properties of PLA/PBAT blown films with chain extender. Polym. Adv. Technol. 2018, 29, 1706-1717. [CrossRef]

34. Farsetti, S.; Cioni, B.; Lazzeri, A. Physico-mechanical properties of biodegradable rubber toughened polymers. Macromol. Symp. 2011, 301, 82-89.

35. Tabasi, R.Y.; Ajji, A. Tailoring Heat-Seal Properties of Biodegradable Polymers through Melt Blending. Int. Polym. Process. XXXII 2017, 5, 607-613. [CrossRef]

36. Gigante, V.; Canesi, I.; Cinelli, P.; Coltelli, M.B.; Lazzeria, A. Rubber Toughening of Polylactic Acid (PLA) with Poly(butylene adipate-coterephthalate) (PBAT): Mechanical Properties, Fracture Mechanics and Analysis of Ductile-to-Brittle Behavior while Varying Temperature and Test Speed. Eur. Polym. J. 2019, 115, 125-137. [CrossRef]

37. Najafi, N.; Heuzey, M.C.; Carreau, P.J. Polylactide (PLA)-clay nanocomposites prepared by melt compounding in the presence of a chain extender. Compos. Sci. Technol. 2012, 72, 608-615. [CrossRef]

38. Li, X.; Yan, X.; Yang, J.; Pan, H.; Gao, G.; Zhang, H.; Dong, L. Improvement of Compatibility and Mechanical Properties of the Poly(lactic acid)/Poly(butylene adipate-co-terephthalate) Blends and Films by Reactive Extrusion With Chain Extender. Polym. Eng. Sci. 2018, 58, 1868-1878. [CrossRef]

39. Lu, X.; Zhao, J.; Yang, X.; Xiao, P. Morphology and properties of biodegradable poly (lactic acid)/poly (butylene adipate-co-terephthalate) blends with different viscosity ratio. Polym. Test. 2017, 60, 58-67. [CrossRef]

40. Favis, B.D.; Chalifoux, J.P. The Effect of Viscosity Ratio on the Morphology of Polypropylene/Polycarbonate Blends During Processing. Polym. Eng. Sci. 1987, 27, 1591-1600. [CrossRef] 
41. Yu, W.; Zhou, W.; Zhou, C. Linear viscoelasticity of polymer blends with co-continuous morphology. Polymer 2010, 51, 2091-2098. [CrossRef]

42. Pötschke, P.; Paul, D.R. Formation of Co-continuous Structures in Melt-Mixed Immiscible Polymer Blends. J. Macromol. Sci. C Polym. Rev. 2003, 43, 87-141. [CrossRef]

43. Omonov, T.S.; Harrats, C.; Moldenaers, P.; Groeninckx, G. Phase continuity detection and phase inversion phenomena in immiscible polypropylene/polystyrene blends with different viscosity ratios. Polymer 2007, 48, 5917-5927. [CrossRef]

44. Jalali Dil, E.; Carreau, P.J.; Favis, B.D. Morphology, miscibility and continuity development in poly(lactic acid)/poly(butylene adipate-co-terephthalate) blends. Polymer 2015, 68, 202-212. [CrossRef]

45. Serban, D.A.; Weber, G.; Marsavina, L.; Silberschmidt, V.V.; Hufenbach, W. Tensile properties of semi-crystalline thermoplasticpolymers: Effects of temperature and strain rates. Polym. Test. 2013, 32, 413-425. [CrossRef]

46. Gan, Z.; Kuwabara, K.; Yamamoto, M.; Abe, H.; Doi, Y. Solid-state structures and thermal properties of aliphaticearomatic poly(-butylene adipate-co-butylene terephthalate) copolyesters. Polym. Degrad. Stabil. 2004, 83, 289-300. [CrossRef]

47. Signori, F.; Coltelli, M.B.; Bronco, S. Thermal degradation of poly(lactic acid) (PLA) and poly(butylene adipate-co-terephthalate) (PBAT) and their blends upon melt processing. Polym. Degrad. Stabil. 2009, 94, 74-82. [CrossRef]

48. Jiang, L.; Wolcott, M.P.; Zhang, J. Study of biodegradable Polylactide/Poly(butylene adipate-co-terephthalate) Blend. Biomacromolecules 2006, 7, 199-207. [CrossRef]

49. Al-Itry, R.; Lamnawar, K.; Maazouz, A. Improvement of thermal stability, rheological and mechanical properties of PLA, PBAT and their blends by reactive extrusion with functionalized epoxy. Polym. Degrad. Stabil. 2012, 97, 1898-1914. [CrossRef]

50. Walsh, D.J.; Rostami, S. The miscibility of high polymers: The role of specific interactions. Adv. Polym. Sci. 1985, 70, 119-169.

51. Fox, D.W.; Allen, R.B.; Kroschwitz, J.I. Compatibility. In Encyclopedia of Polymer Science and Engineering, 2nd ed.; Wiley and Sons: New York, NY, USA, 1985; Volume 3, pp. 758-775.

52. Suyatma, N.E.; Copinet, A.; Tighzert, L.; Coma, V. Mechanical and Barrier Properties of Biodegradable Films Made from Chitosan and Poly (Lactic Acid) Blends. J. Polym. Environ. 2004, 12, 1-6. [CrossRef]

53. Nielsen, L.E. Mechanical Properties of Polymers and Composites, II; Marcel Dekker: New York, NY, USA, 1974.

54. Davies, W.E.A. The theory of elastic composite materials. J. Phys. D Appl. Phys. 1971, 4, 1325-1339. [CrossRef] 